\title{
Studying Economics Reduces Overexploitation in a Common Resource Experiment
}

\author{
Nikolaos Georgantzis ${ }^{1}$, José Santiago Arroyo-Mina ${ }^{2}$, Daniel Guerrero ${ }^{3}$ \\ ${ }^{1}$ Department of Economics, Jaume I University, Castellón, Spain \\ ${ }^{2}$ Department of Economics, Pontificia Universidad Javeriana, Cali, Colombia \\ ${ }^{3}$ Department of Economics, Pontificia Universidad Javeriana, Cali, Colombia \\ Email: ngeorgantzis@ugr.es, jarroyo@javerianacali.edu.co,dguerrero@javerianacali.edu.co
}

Received July 24, 2013; revised August 30, 2013; accepted September 9, 2013

Copyright (C) 2013 Nikolaos Georgantzis et al. This is an open access article distributed under the Creative Commons Attribution License, which permits unrestricted use, distribution, and reproduction in any medium, provided the original work is properly cited.

\begin{abstract}
This paper studies the economical behavior of agents, who make decisions regarding the sustainability of Common-Pool Resources (CPR). For this purpose, economical experiments are applied to simulate the yield of a CPR taking into account the influence of economical training on the learning process of individuals regarding their decisions for sustainability. Based on a non-cooperative game with simultaneous choices, the results of experiments show that after several rounds the existence of economical knowledge reflects a better learning process for making decisions regarding sustainability of CPR.
\end{abstract}

Keywords: Common-Pool Resources; Non-Cooperatives Games; Learning Processes

\section{Introduction}

Economic theory proposes a set of assumptions to analyze the decisions that an agent makes. These assumptions suggest that the agent has a set of preferences with consistent and complete information on relevant aspects of their environment. To understand the assumptions of behavior of an agent, Nash [1] suggests that the agent has unlimited skills that are used to estimate the best decision; in other words, to achieve his highest welfare and predict any kind of consequences that derive their decisions.

In contrast, Simon [2] noted that the agent's decisions are derived from conditions significantly different to the assumptions of economic theory. These conditions are defined as limitations in the choices of the agent. Such limitations are focused on the principle that agents at the moment of making decisions have incomplete knowledge of the context about a particular situation, they have limited cognitive skills that impede them to process all available information to make choices, nor they can anticipate events that affect their decisions; these limitations define the concept of bounded rationality ${ }^{1}$, such as:

\footnotetext{
${ }^{1}$ The concept of bounded rationality emerges as an alternative to classical rationality prevailing in the economic theory. Simon [3] shows that there are choice situations, explaining to encourage new developments that challenge the classical rationality in economics. For example, Plata \& Mejia [4] show that situations of imperfect competition (oligopoly) and the expectations and uncertainty are good examples of bounded rationality.
}

1) Limited and non-perfect knowledge about the environment which the agent is into; 2) the agents face the incapability to consider every alternative to solve a problem; and 3 ) the available information is impossible to assimilate.

Referring to the analysis of market decision making, Bowles [5] argues that agents are adaptive and fallow to establish rules to minimize the costs derived from cognitive limitations when facing situations of the complex analysis, then the agents behave according to the context to determine whether a behavior is appropriate or not in a given scenario, referring themselves to the current state or to the experienced by another agent, deriving a process of transmission of information and establishing the motivations and incentives in decision making.

From above, the baseline of this paper combines the results of Ostrom et al. [6], and Cardenas \& Ostrom [7] according to the relevance for studying the behavior of the logics about individual and collective rationality of agents regarding the decisions of sustainability of CPR. Due to this reason, an economical experiment is developed where a CPR yield is simulated allowing to analyze dilemma that the agent is into, deciding whether to yield the amount of CPR, which maximizes his private benefits, or to yield the amount of CPR, which maximizes the social benefits of the group, he participates.

The structure of the paper that includes this introduction is organized followed by Section 2 where is featured 
the theoretical model for the designed methodology and the applied economical experiments. Next, Section 3 describes the applied of the experiments and the procedures to conduct them. Section 4 shows the analysis and the interpretation of the results obtained for the conduction of the experiments. Finally, Section 5 is presented with some final comments.

\section{Theoretical Model $^{2}$}

The proposed model performs the social dilemma of CPR yield, where the aggregated decisions of agents converge to Nash-Cournot equilibrium, even so to Walrasian equilibrium. ${ }^{3}$

According to Ostrom et al. [6], and Cardenas [8], where an agent decides to assign an effort level for CPR yield, considering also the yield decisions of the $N$ additional CPR's users, therefore assume a maximizer agent $i$ into a static scenario, ${ }^{4}$ having an objective function defined by his own productive effort level $x_{i}$, besides the aggregated effort level $\sum x_{j}$ from the others CPR users who interact with him. Hereby, the private benefit function is defined as:

$$
Y_{i}=\left(x_{i}, \sum_{j=1}^{N} x_{j}\right)
$$

Focus on (1), it is assumed that when the private yield increases, the private revenue increases too. This condition is defined for:

$$
\frac{\partial Y_{i}}{\partial x_{i}}>0
$$

Furthermore, it is assumed that the marginal revenues of private effort are decreasing, therefore:

$$
\frac{\partial^{2} Y_{i}}{\partial x_{i}^{2}}<0
$$

then, due to the resource rivality condition, when the aggregated yield increases, the private welfare decrees, it is so:

$$
\frac{\partial Y_{i}}{\partial x_{j}}<0
$$

Following above, it can be assumed that each agent

\footnotetext{
${ }^{2}$ The theoretical model presented for the design of economical experiments is translated from Arroyo \& Guerrero [9].

${ }^{3}$ The Walrasian competitive equilibrium defines the prices such as a mechanism that coordinate the consumer individual actions, leading net demanded quantities to be equivalent to available supplied quantities on market (Walras [10]).

${ }^{4}$ According to Gibbons [11], and Shy [12] assumptions, the agents have a complete information structure that allow them to have a rational decision making in a simultaneous way, ergo the agents find a long term equilibrium where the resource yield is equal to the resource natural growth. The interested reader can find a broader explanation on Clark [13].
}

has a maximum effort level $e_{i}$, reflecting the decreasing marginal revenues of labor: ${ }^{5}$

$$
g\left(x_{i}\right)=a x_{i}-\frac{1}{2} b x_{i}^{2}
$$

In (2), $a$ and $b$ are positive parameters of agents productivity. Furthermore, $x_{i} \in\left[0, e_{i}\right]$. This function implies that the agent can yield up to the maximum sustainable yield level:

$$
x^{M S Y}=\frac{a}{b}
$$

which indicates the agent obtains positive marginal revenues; nevertheless, yield amounts larger than $x^{M S Y}$ would provide negative marginal revenues. Considering the aggregated yield, and what each $j$ agent does not yield, it is defined the private benefit objective function to maximize:

$$
Y_{i}=a x_{i}-\frac{1}{2} b x_{i}^{2}+\varphi \sum_{j=1}^{N}\left(e_{j}-x_{j}\right)
$$

In (3), the $\varphi$ parameter represents the cost assumed by agent $i$ caused by the externality imposed by the aggregated yield of agents. If it is assumed, that every single agent has same yield technology, and their endowments are equal, it is proposed yield capabilities symmetry, then $e=e_{i}$, and defining (3) as:

$$
Y_{i}=a x_{i}-\frac{1}{2} b x_{i}^{2}+\varphi n e-\varphi \sum_{j=1}^{N} x_{j}
$$

where $n$ is the amount of CPR user. In (4), each (player) agent $i$ chooses a level of yield $x_{i}$, looking for maximize his own private benefits, then:

$$
x^{N}=\frac{a-\varphi}{b}
$$

In (5), it is assumed a strictly positive yield $x^{N} \in\left(0, e_{i}\right]$. The expression (5) is a solution that depends on the parameters $a$ and $b$, also on the externality cost parameter $\varphi$. This solution, as Ostrom et al. [6] proposed, does not take into count on the amount of CPR users, also is considered as the individual competitive solution.

On other hand, it is proposed the social optimum ${ }^{6}$ by the expression:

$$
W=\sum Y_{i}=a \sum x_{i}-\frac{1}{2} b \sum x_{i}^{2}+\varphi n^{2} e-n \varphi \sum x_{i}
$$

${ }^{5}$ Gordon [14] developed the model of open access is developed; this model indicates that natural resources face biologic adversities, including the extinction possibility. In this model, the effort level increases will bring decreasing marginal revenues of labor, and so, when the natural growth is exceeded, these revenues will be progressively derived in smaller yield levels.

${ }^{6} \mathrm{~A}$ social optimum or Pareto-efficient is an allocation of resources where every single agent enjoys his greatest welfare, given the utility function of others (Varian, 1998). 
In (6), it is expressed aggregated benefit of the CPR yield to every user. Assuming the maximizer agents, it is obtained:

$$
x^{S}=\frac{a-n \varphi}{b}
$$

Taking into account (7), as long as more users are involved into the CPR yield the amount of $x^{S}$ decreases. Therefore, it is concluded by Ostrom et al. [6] that an amount $n$ of users bigger than $1(n>1)$, will lead to $x^{S}<$ $x^{N}$, and the associated social dilemma of CPR.

\section{Experimental Design}

This experimental design studies the behavior of agents towards the learning in order to accomplish the benefits maximization considering the sustainability of CPR, according the suggested by Ostrom et al. [6] and Cardenas [8]. The solution presented in (8), defines the individual yield that maximizes the private benefits, i.e.:

$$
x^{N}=\frac{a-\varphi}{b}
$$

In (8), is presented $a$ : the revenue per yielded unit; $b$ : the cost that players assume for the decreasing marginal productivity; $\varphi$ : the cost of the externality imposed by the depletion of the CPR; and $n$ : number of players. From Cardenas [8], it is suggested that $a=60, b=5, \varphi=20$. There by, the yield that maximizes private benefit is defined by:

$$
x^{N}=\frac{a-\varphi}{b}=\frac{60-20}{5}=8
$$

Indicating that player maximizes his benefits when he yields 8 units.

Equation (7) presents the solution that defines the individual yield that maximizes social benefit. Considering that in each group participate, a maximum of 5 players $(n$ $=5$ ), the obtained result is:

$$
x^{S}=\frac{a-n \varphi}{b}=\frac{60-5(20)}{5}=-8
$$

Although, as pointed by Cardenas [8] the yield must be strictly positive, thereby the minimum possible yield is:

$$
x^{S}=1
$$

Having these two solutions, the set of possible extraction of each player is within a discrete range between 1 and 8 complete units. Hence, each player will define the best strategy, considering the best possible strategies of other players.

For those reasons, as a hypothesis to evaluate in this economic experiment, it is stated that:

The level of knowledge in economic theory, and deci- sions of previous periods affect the economical behavior of players for sustainability of CPR. Specifically, the more level of knowledge in economics, the better learning process regarding decision for CPR sustainability; therefore, the average yield decision $x_{i}$ of each player during rounds $6-10$ of experiment must reduces for the learning gained by the player during rounds $1-5$.

The former hypothesis is funded on the changes of teaching methodologies of economics in the last 15 years, where it has switched from an individual training to cooperative learning groups. According to above, Bartlett [15] points out that this kind of methodologies is based on a structure those incentives competences on students to maximize their collective work in order to accomplish common goals. Likewise, Fox [16] assures that co-operative learning obtained by students onto their basic courses allows every single student to look for beneficial results for the group, even so for himself.

Finally, another major change in the method of teaching of economics focuses on the design and implementation of experiments in class. To Noussir \& Walker [17], the use of experiments in teaching of economics stimulates interest of the student, provides demonstrations of the principles of the subject in reality and reflects the limitations of the models taught in undergraduate courses. Additionally, as suggested Yandell [18], the application of experiments in class contributes positively to the learning experience, the interest and satisfaction of students.

\subsection{Experiment Application ${ }^{7}$}

The applied economical experiments recreate a lab in which individuals simulate the extraction of a CPR like fishing. They were performed at the Pontificia Universidad Javeriana Cali, and Universidad Santiago de Cali, Colombia, along the months of February and September 2011.

Players observed in the experiment are: undergraduate students of Economy, Business Administration, Accounting and Finance, Law, Architecture, Psychology, and graduate students in Environmental Management and Sustainable Development and Environmental Education Master from both universities.

The economical experiment includes a sample of 245 players. Experiments were conducted forming groups of five players, each with a monitor that supported in specific situations. Before starting the game, players were presented an exhibition of the context of the experiment, the rules, also were explained that individual pay-offs depended on their own yield besides the aggregate of yield from your competitors. All pay-offs were paid in

${ }^{7}$ In Appendix A is shown the protocol, the suggested instructions to players, the individual decision making formats and the table of points that were used in the experiment. 
monetary form. ${ }^{8}$

\subsection{Experiment Instructions}

Each player was given a sheet where he should indicate each round, the number of individual CPR's yield (e.g., number of fish caught) which player considered optimal. Additionally, it was given to each player a sheet where it was compiled individual and aggregated yielded amount of the group. Being a simultaneous non-cooperative game, only monitor knew the individual amount of each group member, therefore announcing the yielded aggregated amount within the group at the end of each round. Finally, it was provided to each player a table with pay-offs they would receive once the yielded amount by the group was announced.

Each session of experiments was performed in 10 rounds. In each round each player simultaneously chose a yield level of $x_{i}$ CPR among 1 and 8. Therefore, the aggregated level $\sum x_{j}$ had a minimum of 5, and a maximum of 40 units.

The pay-off received for each player in each round, as suggested by Ostrom et al. [6], and Cardenas (2010a), can be expressed by:

$$
w_{i}=f\left(\sum x_{j}-x_{i}\right)
$$

where $w_{i}$ is the individual pay-off in each round, which included a minimum of 198 points, where $x_{i}=1$, and $\sum x_{j}=32$, which is the maximum possible amount of aggregated yield of competitors when every single yielded 8 units. Also, the maximum individual score of 880 points, obtained when $x_{i}=8, \sum x_{j}=4$, when each competitor yielded only 1 unit.

\section{Results}

As already explained, the applied economical experiment studies the behavior of agents regarding the decision in favor of the sustainability of CPR, considering that a higher level of knowledge in economics reflects a better learning process for this kind of decisions. Particularly, experiment analyzes whether average yield decisions $x_{i}$ of each player during rounds 6 - 10 decreases due to the learning gained by the player during rounds $1-5$.

\subsection{Descriptive Analysis}

This economic experiment includes sample of 245 players, who were asked their level of knowledge in economic theory, sex, age and years of schooling. The sample includes 132 men, and 113 women players. Table 1 summarizes the information of the sample.

\footnotetext{
${ }^{8}$ The accumulated score in the experiment was converted to a monetary figure in Colombian pesos, which is paid once the experiment ended. The average paid was $\$ 6.60$ per player.
}

Before showing the econometric analysis of the experimental results, a chart is presented below in Figure 1 with the average extraction of players during rounds 1 - 5 (stage 1) and 6 - 10 (stage 2).

The results suggest that average yield decisions of players are influenced by their initial periods as suggested by the work of Huck et al. [19], Rassenti et al. [20], and Fajfar [21]. Particularly, the results show that the average decrease from 4.94 units extraction during rounds 1 - 5 (formation of knowledge), to 4.91 units during rounds 6 - 10 (learning for sustainable yield decisions).

\subsection{Economics Knowledge and Sustainability Decisions of CPR}

To analyze the behavior of the players based on the learning obtained in the experiment during rounds 1 5considering that more knowledge in economics theory reflects a greater commitment to sustainable yield decisions for CPR, it is defined that the average extraction $x_{i}$ obtained by each player for rounds 6 - 10 of the experiment, was less than or equal to the average extraction obtained during rounds $1-5$. Thereby, each participant with his profile (other academic training than economics) will recognize extraction levels that allow him to get the highest scores in the experiment considering the sustainability of a CPR, as seen in Table 2 .

The results reported in Table 2 stands out two situations:

Table 1. Summary of information from fishermen.

\begin{tabular}{cccc}
\hline & Average & Min & Max \\
\hline Years of Schooling & 13.2 & 5 & 18 \\
Age & 26.5 & 16 & 65 \\
\hline
\end{tabular}

Source: Proper estimations from applied experiments.

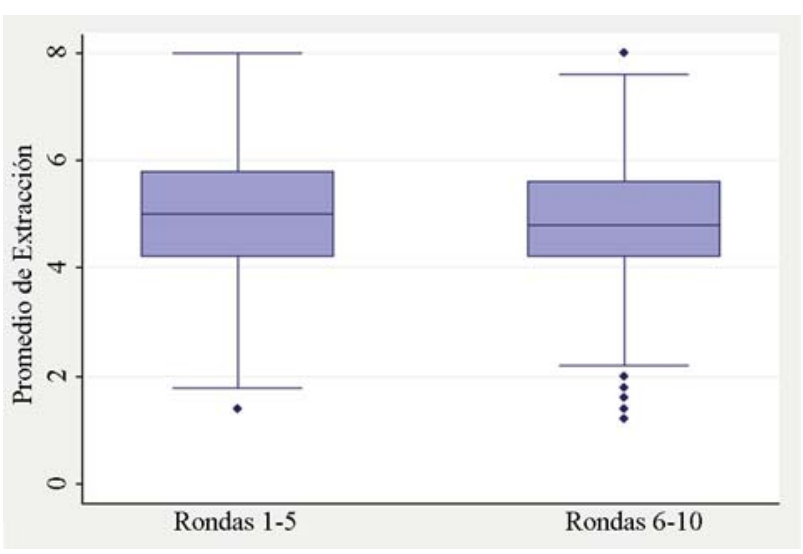

Figure 1. Average yield: Rounds 1 - 5 vs. Rounds 6 - 10 . Source: Proper estimations from applied experiments. The change from stage 1 to stage 2 is statistically significant at $5 \%$. 
Table 2. Average yield by groups.

\begin{tabular}{ccc}
\hline Groups of Students & Rounds 1 - 5 & Rounds 6 - 10 \\
\hline Economics & 5.33 & 5.32 \\
Accounting & 5.13 & 4.83 \\
Environmental $^{*}$ & 4.58 & 4.54 \\
Business Admin $^{*}$ & 5.11 & 5.06 \\
Psychology & 4.70 & 5.60 \\
Architecture & 4.07 & 3.80 \\
Law & 4.55 & 4.18 \\
\hline
\end{tabular}

Source: Proper estimations from applied experiments. ${ }^{*}$ Student of postgraduate programs with orientation to natural resource sustainability.

1) All participants in the experiment except the group of psychology students follow the same trend of decreasing in the average extraction $x_{i}$ obtained during rounds $6-10$, compared to the rounds $1-5$. Additionally, the performance of the group of law students turns out particular. The average extraction decisions of this group during rounds $6-10$, rounds compared to $1-5$ decreases $8.24 \%$, showing a greater learning process with relation to their sustainable yield decisions CPR. This result is consistent with the hypothesis formulated for the experiment, due to the curriculum of law program includes courses in economics, which could facilitate the learning process in the experiment because the elements, instruments and methods of analysis that provides the training in economics. ${ }^{9}$

2) The group of psychology students did not follow the suggested behavior on the formulated hypothesis for experimental design: the average yield decisions increased $19.15 \%$ in rounds $6-10$ compared to rounds $1-5$. In other words, the behavior of psychology students did not adjust towards sustainable yield decisions of CPR in rounds $6-10$ of the experiment as the other participants did. This situation could be the result of the schooling curriculum of psychology, inasmuch as excludes assignments of economics theory, bounding the learning process in the experiment.

Besides from the above results, it is interesting to examine the behavior of players when is involved the schooling years variable in the analysis of learning process regarding sustainable decisions of CPR as is shown in Figure 2.

This result suggests that in experiment, after 13.2 years of average schooling, extraction decisions will decrease as years of schooling increase. Particularly, and as suggested by Becker [22], and Brock \& Durlauf [23], the processes of human capital formation reward the agent

\footnotetext{
${ }^{9}$ This result is consistent to suggested by Bartlett [15] due to the students of disciplines related to economics have within their curriculum courses of Microeconomics and Game Theory, which are based on environments of cooperative learning that allow individuals to learn more and more efficiently.
}

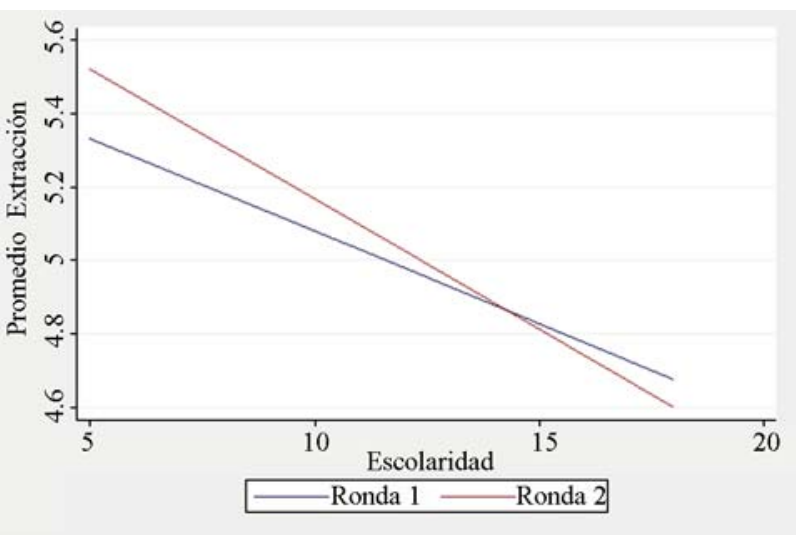

Figure 2. Average yield and schooling years. Source: Proper estimations from applied experiments. The change from stage 1 to stage 2 is statistically significant at $5 \%$.

who decides to participate in them, and society as a whole. Thus, the experiment evidenced that the higher level of education of participants, the better learning process regarding sustainable decisions of CPR (6 - 10 rounds during extraction average reaches 4.13 if 18 years of education).

\subsection{Empirical Analysis}

Considering that applied economical experiment has transverse cutting units (players) with information that is observed during periods $T_{i}$ (10 rounds of the experiment), a static model of panel data with conjoint regression $^{10}$ is presented:

$$
y_{i t}=x_{i t}^{\prime} \beta+e_{i t}, i=1, \cdots, N, t=1 \cdots T_{i}
$$

As suggested by Baltagui [24], and Hsiao [25], this model identify the specific individual effects that are not included in the estimation, i.e., this model points out the effect that determinants appointed above might influence on the sustainability decisions of CPR.

\subsection{Interpretation of Results}

The estimations of econometric model contrast the average yield decisions of each player during rounds $6-10$, with those obtained in rounds $1-5$, considering the determinants already mentioned, focusing on the existence of economics theory training as shown in Table $3 .^{11}$

The results show that the signs of the estimated parameters in the model behave as expected. Thus, to vali-

\footnotetext{
${ }^{10}$ With the encouragement that the model consider all the assumptions that allow to prove empirically the theoretical hypothesis already mentioned, it captures the non-observed effect in the model, from the inclusion of a parameter for each individual in the regression as suggested by Baltagui [24], and Hsiao [25]

${ }^{11}$ For convenience in the edition of the table is not displayed the information of each estimation by group of participants, however, each of the estimated models has a R-squared between 0.90 and 0.98, i.e. the estimations are correct.
} 
Table 3. Economics knowledge and learning regarding CPR sustainability.

\begin{tabular}{ccccc}
\hline Players & Coef. & p-value & \multicolumn{2}{c}{$[95 \%$ Conf. Interval $]$} \\
\hline Economics & 0.15933 & 0.000 & 0.134146 & 0.184527 \\
Accounting & 0.11399 & 0.000 & 0.095092 & 0.132889 \\
Environmental $^{*}$ & 0.09709 & 0.000 & 0.091509 & 0.102688 \\
Business Admin $^{*} 0.12552$ & 0.000 & 0.116807 & 0.134247 \\
Psychology & 0.12683 & 0.000 & 0.112492 & 0.141174 \\
Architecture & 0.10927 & 0.000 & 0.087832 & 0.130724 \\
Law & 0.12225 & 0.000 & 0.097773 & 0.146742 \\
\hline
\end{tabular}

Source: Proper estimations from applied experiments. "Student of postgraduate programs with orientation to natural resource sustainability.

date the hypothesis that behavior of players in the experiment regarding sustainable decisions of CPR is influenced by the level of knowledge in economics theory of participants. Particularly, it is accepted that the average extraction $x_{i}$ during rounds 6 - 10 decreases due to learning gained by the player during rounds 1 - 5 considering the level of knowledge in economics theory of the participants.

Particularly, the result of economics student group (increase in $15.93 \%$ during rounds 6 - 10 of the experiment) confirms that more knowledge and training in this discipline influences the sustainable decisions of CPR learning process because the methods of teaching of the discipline enhance the criteria for judging the suitability of these sustainable choices. ${ }^{12}$

Additionally, the other groups of students who participated in the experiment reflect a similar behavior as a function of the effect of the level of knowledge in economics on its preservation decisions by CPR. Specifically, their sustainability decisions for CPR during rounds 6 - 10 experiment $12.05 \%$ increase on average. Regarding the performance of the players when considering their ages, education and sex, a table is presented summarizing the results of the estimated model according to econometric methodology described above.

Table 4 shows that the signs of the estimated parameters for the selected econometric model behave as expected. Regarding the educational level, the result shows that for each additional year in the level of schooling of participants compared to the average schooling years of the sample (13.2), extraction decisions for the sustainability of RUC increased $8.4 \%$, confirming that recorded in Becker [22], and Brock \& Durlauf [23] for the processes of human capital formation.

\footnotetext{
${ }^{12}$ This kind of behavior suggests that the level of expectations of players combined with their expected choice error, behavior of CPR sustainability are formed: "If people give importance to a particular value associated with the conservation, one can expect a positive assessment to the activities that promote conservation. Economists say that individuals gain greater utility" (Lynne et al. [26]).
}

Table 4. Panel data model with conjoint regression.

\begin{tabular}{ccccc}
\hline Lyield $^{13}$ & Coef. & p-value & \multicolumn{2}{c}{$[95 \%$ Coef. Interval $]$} \\
\hline Age & 0.0012188 & $0.061^{*}$ & -0.003519 & -0.006956 \\
Schooling & 0.0847114 & 0.000 & 0.0707961 & 0.0986267 \\
Sex & 0.2579147 & 0.000 & 0.1739859 & 0.3418438 \\
\hline
\end{tabular}

Source: Proper estimations from applied experiments. "Statistically significant at $10 \%$. The others at $5 \%$.

Furthermore, although the age variable turns out to be statistically significant, it can be noticed that having more or less years compared to the average age of the participants, only influences a $0.12 \%$ on sustainable decisions of CPR. In other words, if a player is 1 year older than the average age of the sample (26.5 years), he is not guaranteed that learning process for sustainability decisions of RUC is actually more significant. Therefore, this result suggests that the processes of teaching and training in environmental education could focus on all age groups of society.

Regarding the results of the sex variable, the result shows that men learned faster than women in rounds 1 5 in $25.8 \%$, and therefore they adjust their sustainable decisions of CPR faster than women.

\section{Concluding Remarks}

The objective of this paper is to study the behavior of agents when makeing decisions related to the sustainability of Common Pool Resources (CPR). For this purpose, an economical laboratory was recreated where agents simulated the extraction of CPR as fishing. The results presented in this study are a product of economical experiments applied to 245 undergraduate students in economics, accounting, business administration, architecture, psychology, law and graduate students in environmental management and master in environmental education, belonging to two universities in the city of Santiago de Cali, Colombia.

Based on a non-cooperative game with complete information and simultaneous choices, the results of the experiment show that after several rounds the agents have some kinds of learning abilities for sustainable decision of CPR as suggested by Ostrom et al. [6], and Clark [13]. Specifically, the theoretical hypothesis proposed regarding the influence of economics and teaching and training on sustainability decisions of RUC is accepted.

Particularly, it is validated that the existence of a higher level of knowledge of economic theory reflects a better learning process for sustainable decisions of CPR. Thereby, it is demonstrated that average yield $x_{i}$ decision of the group of students with higher levels of knowledge in economic theory, decreased during rounds $6-10$ of

\footnotetext{
${ }^{13}$ The model contains a sample $\mathrm{n}=245, \mathrm{R}^{2}=0.9433, \mathrm{~F}=0.000$.
} 
the experiment for the learning obtained by themselves during rounds $1-5$, guarantying the propose by Huck et al. [19], and Fajfar [21], who claim that agents have a learning curve for their decisions.

Finally, and as a suggestion, future designs of experimental and behavioral economics related to natural resources and sustainability of CPR should take into account: 1) Including different skills from those that economic theory provides, i.e. studying the decisions of agents based on structures unlike cost analyses and benefits. 2) Studying the behavior of agents facing unexpected as global warming, since this type of phenomena may affect the CPR's.

\section{REFERENCES}

[1] J. Nash, "The Bargaining Problem," Econometrica, 1950 Vol. 18, No. 2, 1950, pp. 155-162. http://dx.doi.org/10.2307/1907266

[2] H. Simon, "A Behavioral Model of Rational Choice," The Quaterly Journal of Economics, Vol. 69, No. 1, 1955, pp. 99-118. http://dx.doi.org/10.2307/1884852

[3] H. Simon, "Rationality in Psychology and Economics. Rational Choice: The Contrast between Economics and Psychology," Journal of Political Economy, Vol. 99, No. 4, 1986, pp. S209-S224.

[4] L. Plata and I. Mejia, "Racionalidad Clasica o Racionalidad Limitada?" Archivos Jornadas de Epistemología Económica, Universidad Nacional de Buenos Aires, 2010.

[5] S. Bowles, "Microeconomics: Behavior, Institutions and Evolution," Princeton University Press, Princeton, 2004.

[6] E. Ostrom, R. Gardner and J. Walker, "Rules, Games, and Common-pool Resources," University of Michigan Press, Ann Arbor, 1994.

[7] J. Cárdenas and E. Ostrom, "What Do People Bring into the Game: Experiments in the Field about Cooperation in the Commons," Agricultural Systems, 2004, Vol. 82, No. 3, 2004, pp. 307-326.

http://dx.doi.org/10.1016/j.agsy.2004.07.008

[8] J. Cárdenas, "Dilemas de lo Colectivo: Instituciones, Pobreza y Cooperación en el Manejo Local de los Recursos de uso Común," Colección CEDE 50 años, Facultad de Economía, 2010.

[9] S. Arroyo and D. Guerrero, "Determinantes de Decisiones Sociales Para Preservar Recursos de uso Común: Aplicaciones Experimentales Bajo un Modelo de Aprendizaje a la Cournot," Journal of Management and Economics for Iberoamerica, in process, 2012.

[10] L. Walras, "Elementos de la Teoría Política Pura," Alianza Editores, 1990.

[11] R. Gibbons, "Game Theory for Applied Economists," Princeton University Press, Princeton, 1958.
[12] O. Shy, "Industrial Organization: Theory and Applications," MIT Press, Cambridge, 1995.

[13] C. Clark, "Mathematical Bioeconomics: The Optimal Management of Renewable Resources," Wiley Interscience Publication, Hoboken, 1990.

[14] H. S. Gordon, "The economic Theory of a Common Property Resource: The Fishery," Journal of Political Economy, Vol. 62, No. 2, 1954, pp.124-142. http://dx.doi.org/10.1086/257497

[15] R. Bartlett, "Making Cooperative Learning Work in Economic Classes," In: Becker and Watts (compilers), Eds., Teaching Economics to Undergraduates: Alternatives to Chalk and Talk, 1998.

[16] E. Fox, "Introduction to Cooperative Learning," In: R. T. Johnson and D. W. Johnson, Eds., Methods for Developing Cooperative Learning on the Web, 2001. http://courses.cs.vt.edu/ cs $4624 / \mathrm{s} 01 /$ docs/cooplearning.p $\underline{\mathrm{df}}$

[17] C. Noussir and J. Walker, "Student Decision Making as Active Learning: Experimental Economics in the Classroom," Edward Elgar Publishing Limited, Cheltenham, 1998.

[18] B.H. Baltagi, "Econometric Analysis of Panel Data," John A. Wiley \& Sons, New York, 1995.

[19] S.Huck, H. Normann and J. Oechssler, "Learning in Cournot Oligopoly: An Experiment," The Economic Journal, Vol. 1, No. 8, 1999, pp. 80-96. http://dx.doi.org/10.1111/1468-0297.00418

[20] S. Rassenti, S, Reynolds, V. Smith and F. Szidarovsky. "Adaptation and Convergence of Behavior in Repeated Experimental Cournot Games," Journal of Economic Behaviour and Organization, Vol. 41, No. 2, 2000, pp. 117 146. http://dx.doi.org/10.1016/S0167-2681(99)00090-6

[21] P. Fajfar, "Information and Competition in Cournot's Model: Evidence from the Laboratory," Social Science Research Network, 2006, p. 884231.

[22] G. S. Becker. "Crime and Punishment: An Economic Approach,” The Journal of Political Economy, 1968, Vol. 76, pp. 169-217.

[23] W. BrockandS. Durlauf. "Discrete Choice with Social Interactions," Review of EconomicStudies, Vol. 68, No. 2, 2001, pp. 235-260. http://dx.doi.org/10.1111/1467-937X.00168

[24] D. Yandell, "Effects of Integration and Classroom Experiments on Student Learning and Satisfaction," In: I. S. University and P.-H. P. Co., Eds., Economics and the Classroom Conference, 1999. http://home.sandiego.edu/ yandell/idaho.pdf

[25] C. Hsiao, "Analysis of Panel Data," 2003.

[26] G. Lynne, J. Shonkwiler, and L. Rola. "Attitudes and Farmer Conservation Behavior," American Journal of Agricultural Economics, Vol. 70, No. 1, 1988, pp. 12-18. http://dx.doi.org/10.2307/1241971 


\section{Appendix A. Protocol of Experiments}

The sessions of economical experiments were conducted as follows:

\section{Appendix A1. Information Session}

This session begins with the explanation about what is a Common-Pool Resource CPR. Following, several examples of these natural resources are presented, then it is explained the concepts of rivalry and exclusion. Therefore, the present is introduced and each participant decided whether or not to participate. After forming groups of 5 players the context of the game is presented, the formats of individual choice and points are provided to players (see Appendices B and C), the rules are explained making it clear that the game do not allow interactions between players, and finally how to get individ- ual score. In this session, the players were notified if the pay-offs were going to be paid with money or academic incentives. After the introduction, three rounds of practice were conducted for players to become familiar with the dynamics of the game.

\section{Appendix A2. Application Rounds 1 - 10}

It allowed him to freely choose each player the number of units you want to extract the resource. Each player wrote on Individual extraction format the drives you want to play. The monitor was collecting group at the end of each round individual decisions of each player, with the encouragement of total extracted total power by the group, and then communicate them. Then each player scored his punctuation in dot format. This procedure was repeated until round 10 .

\section{Appendix B. Individual Decision Table}

\begin{tabular}{|c|c|c|c|c|}
\hline \multicolumn{5}{|l|}{ Player No } \\
\hline \multicolumn{5}{|l|}{ Age } \\
\hline \multicolumn{5}{|l|}{ Sex } \\
\hline \multicolumn{5}{|c|}{ Years of scholling } \\
\hline Rounds & A: Individual Amount of Yield & $\begin{array}{l}\text { B: Aggregated Amount of } \\
\text { Yield of Group }\end{array}$ & $\begin{array}{l}\mathrm{C}(\mathrm{B}-\mathrm{A}) \text { : Aggegated Amount of } \\
\text { Yield from other participants }\end{array}$ & D: Score \\
\hline \multicolumn{5}{|l|}{ Practice 2} \\
\hline \multicolumn{5}{|l|}{ Practice 3} \\
\hline \multicolumn{5}{|l|}{1} \\
\hline \multicolumn{5}{|l|}{2} \\
\hline \multicolumn{5}{|l|}{3} \\
\hline \multicolumn{5}{|l|}{10} \\
\hline Total & & & & \\
\hline
\end{tabular}

\section{Appendix C. Individual Score Table}

\begin{tabular}{|c|c|c|c|c|c|c|c|c|}
\hline \multirow[b]{2}{*}{ Aggregated amount of other participants } & \multicolumn{8}{|c|}{ My own amount of yield } \\
\hline & 1 & 2 & 3 & 4 & 5 & 6 & 7 & 8 \\
\hline 5 & 738 & 770 & 798 & 820 & 838 & 850 & 858 & 860 \\
\hline 6 & 718 & 750 & 778 & 800 & 818 & 830 & 838 & 840 \\
\hline 7 & 698 & 730 & 758 & 780 & 798 & 810 & 818 & 820 \\
\hline 8 & 678 & 710 & 738 & 760 & 778 & 790 & 798 & 800 \\
\hline 9 & 658 & 690 & 718 & 740 & 758 & 770 & 778 & 780 \\
\hline 10 & 638 & 670 & 698 & 720 & 738 & 750 & 758 & 760 \\
\hline 11 & 618 & 650 & 678 & 700 & 718 & 730 & 738 & 740 \\
\hline 12 & 598 & 630 & 658 & 680 & 698 & 710 & 718 & 720 \\
\hline 13 & 578 & 610 & 638 & 660 & 678 & 690 & 698 & 700 \\
\hline
\end{tabular}




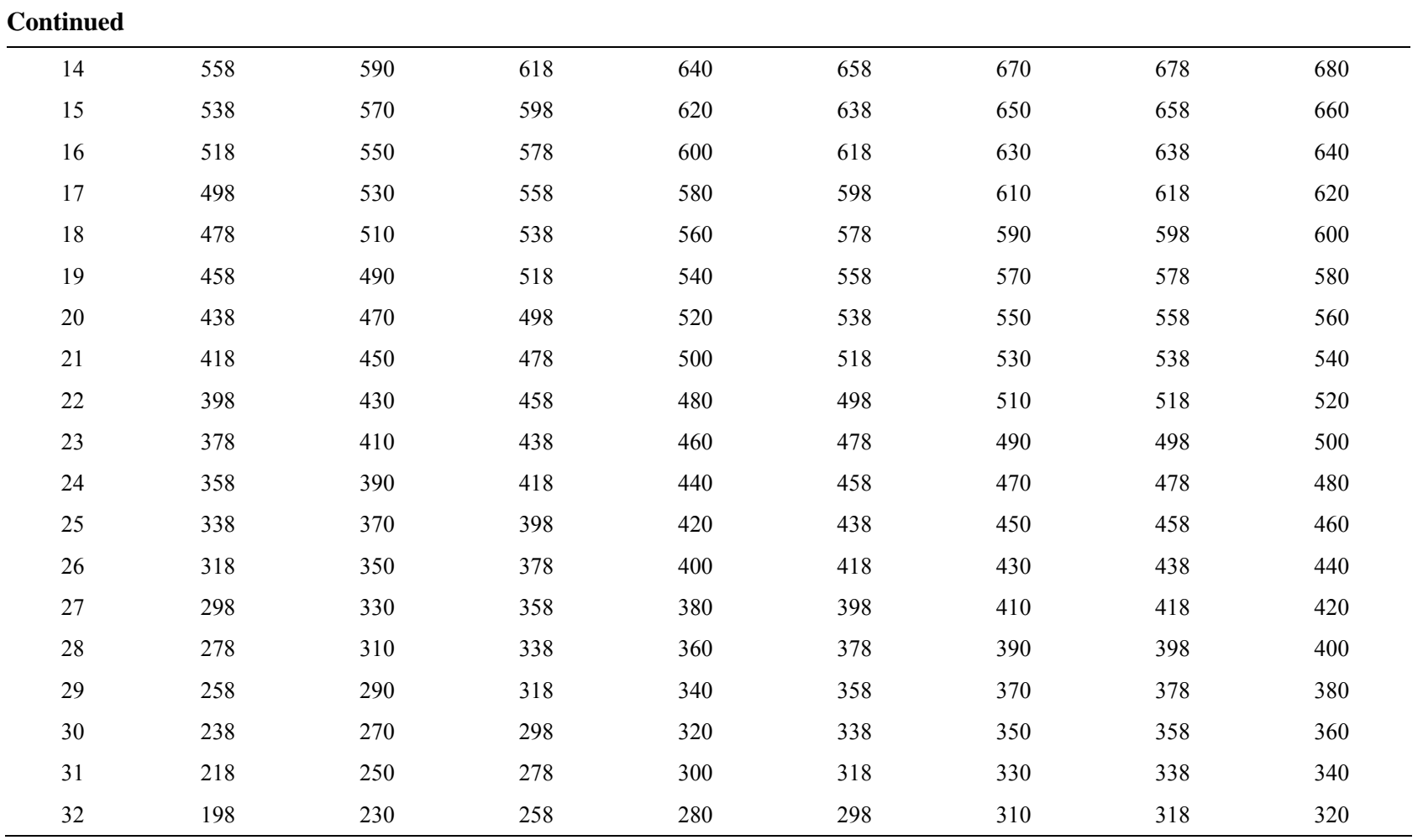

